\title{
In Vitro Cysteine Reactivates Organophosphate Insecticide Dichlorvos-Inhibited Human Cholinesterases
}

$$
\begin{aligned}
& \text { الإضافة للسيستين يعيد تنشيط أننيم كولينستراز البشري التي يثبطها مبيد } \\
& \text { الحشرات العضوية الفوسفاتية الديكلوروفوس }
\end{aligned}
$$

حميد رضا محمدى، جعر جليليان، محمد يحيى كريمي، سيد شتاب بوشهرى

\begin{abstract}
Objectives: Organophosphate (OP) pesticides inhibit both red blood cell (RBC) and plasma cholinesterases (ChEs). Oximes, especially pralidoxime (2-PAM), are widely used as antidotes to treat OP poisoning. In addition, $\mathrm{N}$-acetylcysteine (NAC) is sometimes used as an adjuvant antidote. The current study aimed to assess the feasibility of using NAC as a single therapeutic agent for OP poisoning in comparison to in vitro 2-PAM. Methods: This study was carried out at the Razi Drug Research Center of Iran University of Medical Sciences, Tehran, Iran, between April and September 2014. A total of 22 healthy human subjects were recruited and $8 \mathrm{~mL}$ citrated blood samples were drawn from each subject. Dichlorvos-inhibited blood samples were separately exposed to low and high doses (final concentrations of 300 and $600 \mu \mathrm{mol} . \mathrm{L}^{-1}$, respectively) of 2-PAM, NAC and cysteine. Plasma and RBCs were then separated by centrifugation and their ChE activity was measured using spectrophotometry. Results: Although cysteine-and not NAC-increased the ChE activity of both plasma and RBCs over those of dichlorvos, it did not increase them over those of a high dose of 2-PAM. Conclusion: These results suggest that the direct reactions of 2-PAM and cysteine with dichlorvos and the reactivation of phosphorylated ChEs occurr via an associative stepwise addition-elimination process. High therapeutic blood concentrations of cysteine are needed for the elevation of ChE activity in plasma and RBCs; however, both this agent and NAC may still be effective in the reactivation of plasma and $\mathrm{RBC}$ ChEs.
\end{abstract}

Keywords: Organophosphate Poisoning; Antidotes; Cysteine; N-Acetylcysteine; Pralidoxime Compounds; Cholinesterases.

الملخص: الهدف: مبيدات الفوسفات العضوي هي مواد من صنع الإنسان وهي تثبط انزيم الكولينستراز في كل من خلايـا الدم الحمراء (كرات

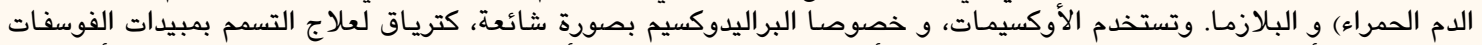

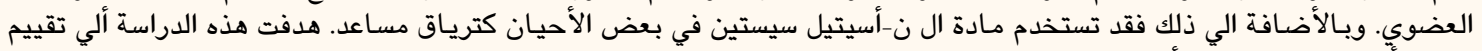

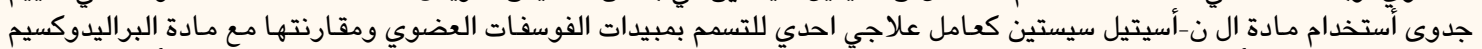

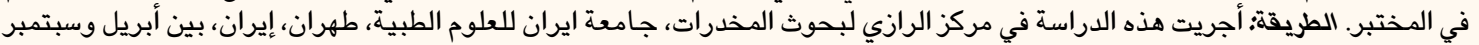

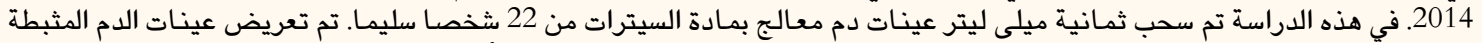

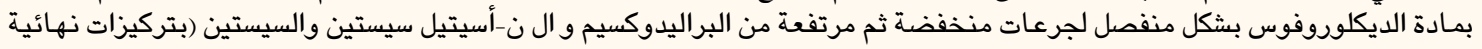

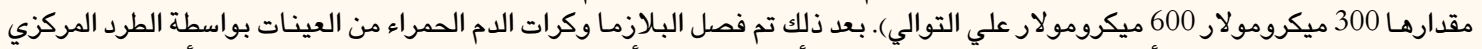

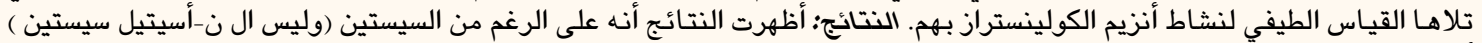

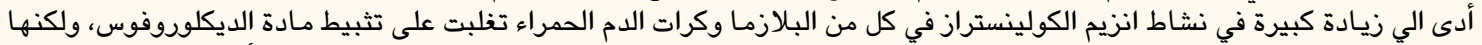

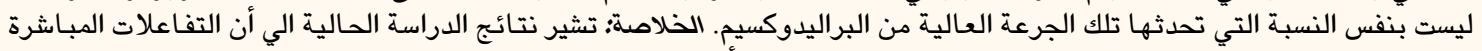

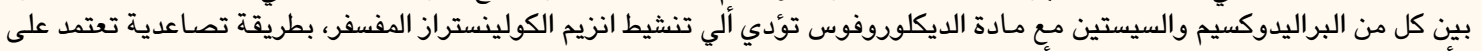

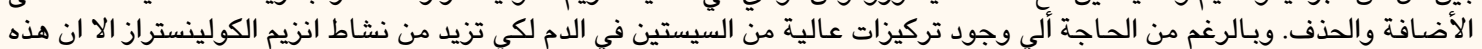

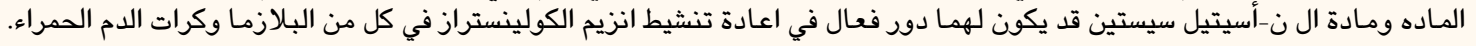

الكلمات المفتاحية: التسمم بمركبات الفوسفات العضوي؛ ترياق؛ السيستين؛ ن-أسيتيل سيستين؛ مركبات البراليدوكسيم؛ انزيم الكولينستراز.

\section{AdVANCES IN KNOWLEDGE}

The results of the present study showed that, although high concentrations of cysteine increased dichlorvos-inhibited acetyl-and pseudocholinesterase activities, this agent was less efficient than pralidoxime in the reactivation of human cholinesterases.

In addition, the study illustrated that cysteine directly reacts with and inactivates dichlorvos at low plasma concentrations, while it replaces serine in the dichlorvos-cholinesterase complex at a very high plasma concentration and regenerates inhibited cholinesterases as well as having a direct reaction with dichlorvos. 
These findings indicate that the effectiveness of cysteine in dichlorvos-induced poisoning depends on both dichlorvos and cysteine plasma concentrations.

Application to Patient Care

According to the findings of this study, the efficacy of cysteine in the treatment of cases of organophosphate poisoning may depend on maintaining high therapeutic concentrations of cysteine.

$\mathrm{O}$ RGANOPHOSPHATE (OP) PESTICIDES ARE MANmade phosphoric acid esters that inhibit and inactivate both true (i.e. acetylcholinesterase $[\mathrm{AChE}]$ ) and pseudo- (i.e. butyrylcholinesterase $[\mathrm{BuChE}])$ cholinesterases (ChEs) by a nucleophilic reaction in which the associative two-step additionelimination reaction with the serine hydroxyl group at their active sites results in phosphorylated and inactivated enzymes. ${ }^{1,2} \mathrm{AChE}$ is primarily found in nervous tissue and erythrocytes; erythrocytic $\mathrm{ChE}$ activity more accurately reflects nervous tissue $\mathrm{AChE}$ activity than $\mathrm{BuChE}$, which is primarily produced in the liver and appears in plasma, with its activity varying with a number of disorders including liver disease. ${ }^{3,4}$ The irreversible inactivation of ChEs by the dealkylation of the OP moiety of the OP-ChE complex is known as ageing, in which the phosphorusoxygen bond of the OP-ChE complex strengthens. ${ }^{5}$ After ageing occurs, even oximes are ineffective in reactivating the enzyme, and the only means of restoring ChE activity is via the lengthy process of synthesizing a new AChE enzyme. ${ }^{2}$

At present, two main antidotes exist for the treatment of OP poisoning: atropine and oximes, particularly pralidoxime (2-PAM) in the latter group. ${ }^{2}$ However, oximes are not always useful in the management of OP poisoning. ${ }^{6-8}$ Moreover, the phosphorylated oxime complex is a strong inhibitor of ChEs and oximes themselves can inhibit AChEs. ${ }^{9}$ Thus, the introduction of new, more efficient and less toxic antidotes to OP poisoning seems necessary. $\mathrm{N}$-acetylcysteine (NAC) is a prodrug of cysteine and a mucolytic agent with potent antioxidant and free radical scavenging properties; it is currently used to treat acetaminophen poisoning and as an adjuvant antidote for OP poisoning. ${ }^{10,11}$ Other medical uses of NAC include the treatment of radiocontrastinduced nephropathy, cyclophosphamide-induced haemorrhagic cystitis and a number of psychiatric disorders. ${ }^{12-14}$ Furthermore, NAC has significant antiviral activity against the influenza $A$ viruses. ${ }^{15}$ The present study aimed to assess the feasibility of cysteine administration as a single therapeutic agent for the reactivation of both $\mathrm{AChE}$ and $\mathrm{BuChE}$ in comparison with in vitro 2-PAM administration.

\section{Methods}

This study was carried out at the Razi Drug Research Center, Iran University of Medical Sciences, Tehran, Iran, between April and September 2014. A total of 22 healthy human subjects were recruited to participate in the study. Each participant was requested to complete a questionnaire to determine their health status, use of medications, occupational history and exposure to pesticides. Subjects with a history of diabetes mellitus, hypertension, liver disease, anaemia, malnutrition, cancer or other chronic illnesses and those who smoked cigarettes, used alcohol or drugs or had a history of radiotherapy were excluded from the study.

The following chemicals and solutions were purchased: 5,5'-Dithiobis(2-nitrobenzoic acid) (DTNB), $\mathrm{N}$-acetylcysteine, cysteine, potassium dihydrogen phosphate, dipotassium hydrogen phosphate, sodium chloride and tripotassium citrate monohydrate (Merck KGaA, Darmstadt, Germany); quinidine sulfate dihydrate, acetylthiocholine iodide and S-butyrylthiocholine iodide (Sigma-Aldrich Corp., St. Louis, Missouri, USA); dichlorvos of $98 \%$ weight/weight purity (Gyah Corp., Karaj, Iran); and 2-PAM methylsulfate (Laboratoires SERB, Paris, France). Stock solutions of dichlorvos, 2-PAM, NAC and L-cysteine were each separately prepared in a $0.9 \%$ weight/volume $(\mathrm{w} / \mathrm{v})$ solution of sodium chloride in distilled water (i.e. normal saline) to produce final concentrations of $21.0 \mu \mathrm{g} \cdot \mathrm{mL}^{-1}\left(95 \mu \mathrm{mol} . \mathrm{L}^{-1}\right), 14.9 \mathrm{mg} \cdot \mathrm{mL}^{-1}\left(60 \mathrm{mmol} . \mathrm{L}^{-1}\right)$, $9.80 \mathrm{mg} \cdot \mathrm{mL}^{-1}$ (60 mmol.L-1) and $7.27 \mathrm{mg} \cdot \mathrm{mL}^{-1}$ $\left(60 \mathrm{mmol}^{\mathrm{L}-\mathrm{L}^{-}}\right.$). All stock solutions were stored in the dark at $4{ }^{\circ} \mathrm{C}$.

An 8-mL blood sample was obtained from each subject and immediately citrated with a $3.8 \%$ $\mathrm{w} / \mathrm{v}$ tripotassium citrate solution to prevent clot formation. ${ }^{16}$ Each sample was then divided into $1 \mathrm{~mL}$ aliquots. The first aliquot was considered as a control and placed in a water bath at $37^{\circ} \mathrm{C}$ for 80 minutes. The second aliquot was exposed to dichlorvos at a final concentration of $0.95 \mu \mathrm{mol} . \mathrm{L}^{-1}$ in a $37^{\circ} \mathrm{C}$ water bath for 80 minutes..$^{17}$ The remaining aliquots were exposed to dichlorvos at a final concentration of $0.95 \mu \mathrm{mol} . \mathrm{L}^{-1}$ in a water bath at $37^{\circ} \mathrm{C}$ for 20 minutes, followed by 
exposure to low and high concentrations of 2-PAM, L-cysteine and NAC separately in a water bath at $37{ }^{\circ} \mathrm{C}$ for 60 minutes. In total, $10 \mu \mathrm{L}$ of the dichlorvos, 2-PAM, NAC and cysteine solutions were added to $1 \mathrm{~mL}$ of blood to produce final concentrations of $0.21 \mu \mathrm{g} \cdot \mathrm{mL}^{-1}\left(0.95 \mu \mathrm{mol} \cdot \mathrm{L}^{-1}\right), 149 \mu \mathrm{g} \cdot \mathrm{mL}^{-1}\left(600 \mu \mathrm{mol} . \mathrm{L}^{-1}\right)$, $98 \mu \mathrm{g} \cdot \mathrm{mL}^{-1}\left(600 \mu \mathrm{mol} . \mathrm{L}^{-1}\right)$ and $72.7 \mu \mathrm{g} \cdot \mathrm{mL}^{-1}$ (600 $\mu \mathrm{mol} . \mathrm{L}^{-1}$ ), representing the high doses of the drugs. An additional $5 \mu \mathrm{L}$ of the 2-PAM, NAC and L-cysteine solutions were added to $1 \mathrm{~mL}$ of blood to produce final concentrations of $74.5 \mu \mathrm{g} \cdot \mathrm{mL}^{-1}$ (300 $\left.\mu \mathrm{mol} . \mathrm{L}^{-1}\right), 49 \mu \mathrm{g} \cdot \mathrm{mL}^{-1}\left(300 \mu \mathrm{mol} . \mathrm{L}^{-1}\right)$ and $36.3 \mu$ g.mL- ${ }^{-1}\left(300 \mu \mathrm{mol} . \mathrm{L}^{-1}\right)$, representing the low doses of the drugs.

The plasma and red blood cells (RBCs) of each blood sample were then separated by centrifugation at 5,000 revolutions per minute for 10 minutes. Each plasma sample was diluted 100 times with distilled water and the diluted sample was used to determine BuChE activity. Each volume of the RBC sample was first washed three times with three volumes of normal saline and then haemolyzed and diluted 60 times with distilled water to sufficiently dilute thiol-containing (i.e. cysteine and NAC) and oxime-containing (i.e. 2-PAM) compounds and prevent reactions with DTNB. The haemolyzed diluted sample (haemolysate) was used to determine AChE activity. Ellman's kinetic method was used to determine the BuChE and $\mathrm{AChE}$ activities of diluted samples at 410 and $440 \mathrm{~nm}$, respectively. ${ }^{18}$

In order to measure BuChE activity, $50 \mu \mathrm{L}$ of the diluted plasma sample was added to $150 \mu \mathrm{L}$ of a reagent containing $0.423 \mathrm{mmol}^{-\mathrm{L}^{-}}{ }^{-}$of DTNB in $0.1 \mathrm{~mol}^{\mathrm{L}-{ }^{-}}{ }^{-}$of a phosphate buffer with a $\mathrm{pH}$ of 7.6 as well as $50 \mu \mathrm{L}$ of substrate (10 mmol.L- ${ }^{-1}$ of butyrylthiocholine iodide in distilled water) in each well of a 48-well plate and marked as a test well. All components of the test well were included in five blank wells, except for the sample which was replaced by an equivolume of normal saline. Initial and final absorbances of the test and blank wells were then recorded at $410 \mathrm{~nm}$ over a 5-minute period. Test well absorbances were subtracted from the average absorbance of the blank wells and divided by 0.0216 as the product of the time period and the molar attenuation coefficient of the 5-thio-2-nitrobenzoate anion at $410 \mathrm{~nm}\left(0.0136 \mathrm{~L} \cdot \mu \mathrm{mol}^{-1} \cdot \mathrm{cm}^{-1}\right)$ and light path length $(0.318 \mathrm{~cm})$ and multiplied by the dilution factor $(100 \times 5=500)$.

Subsequently, AChE activity was measured using $10 \mu \mathrm{L}$ of the haemolysate sample added to 300 $\mu \mathrm{L}$ of a reagent containing 0.27 mmol.L- ${ }^{1}$ of DTNB and $20 \mu \mathrm{mol.L-}{ }^{1}$ of quinidine sulfate in $0.1 \mathrm{mol.L}^{-1}$ of a phosphate buffer at a $\mathrm{pH}$ of 7.6 and preincubated for 5 minutes at $37{ }^{\circ} \mathrm{C}$. This procedure was followed by the addition of $10 \mu \mathrm{L}$ of substrate (100 mmol.L-1 of acetylthiocholine iodide in distilled water) in each well of a 48-well plate and marked as a test well. As before, five blank wells contained all components of the test well, except for the sample, which was replaced by an equivolume of normal saline. The initial and final absorbances of the test and blank wells were recorded during a 5 -minute period at $440 \mathrm{~nm}$. The absorbances of the test wells were subtracted from the average absorbance of the blank wells and divided by 0.023 as the product of the time period and the molar attenuation coefficient of the 5-thio-2-nitrobenzoate anion at $440 \mathrm{~nm}\left(0.01434\right.$ L. $\left.\mathrm{mol}^{-1}{ }^{1} \mathrm{~cm}^{-1}\right)$ and light path length $(0.32 \mathrm{~cm})$ and multiplied by the dilution factor $(60 \times 32=1,920)$. The visible absorbances of samples were measured using a multi-mode microplate reader (Synergy $^{\mathrm{TM}}$ HT Microplate Reader, BioTek Instruments Inc., Winooski, Vermont, USA).

All BuChE and AChE activities were expressed in units per L $\left(U^{-}-^{-1}\right)$. The activity of each sample was divided by that of the respective control (normalisation) and represented as a percentage. A onesample t-test was used to analyse the statistical differences between the percentages of BuChE and AChE activities in the dichlorvos and control groups, for which the latter was deemed to have 100\% ChE activity. Differences between percentages of $\mathrm{BuChE}$ and $\mathrm{AChE}$ activities in the experimental groups were analysed using a one-way analysis of variance test followed by a Scheffe post-hoc test. The Statistical Package for the Social Sciences (SPSS), Version 23.0 (IBM Corp., Armonk, New York, USA) was used for all statistical analyses. A $P$ value of $<0.050$ was considered statistically significant. Graphs were produced using SigmaPlot software, Version 12.0 (Systat Software Inc., San Jose, California, USA).

This study was approved by the Ethics Committee of the Mazandaran University of Medical Sciences, Sari, Mazandaran, Iran (\#1072). All procedures were performed in accordance with the ethical standards of the revised Declaration of Helsinki of 2008. All participants signed an informed consent form before being included in the study.

\section{Results}

Dichlorvos significantly reduced BuChE activity in comparison to the control group $(37.8 \% \pm 2.5 \%$; $P<0.010)$. Both low and high doses of 2-PAM (55.0\% $\pm 3.5 \%$ and $72.0 \% \pm 3.4 \%$, respectively) significantly increased BuChE activity in comparison to the dichlorvos group $(P<0.010$ and $<0.001$, respectively). Low concentrations of NAC and cysteine $(38.8 \% \pm 2.0 \%$ and $35.5 \% \pm 2.7 \%$, respectively) did not significantly 


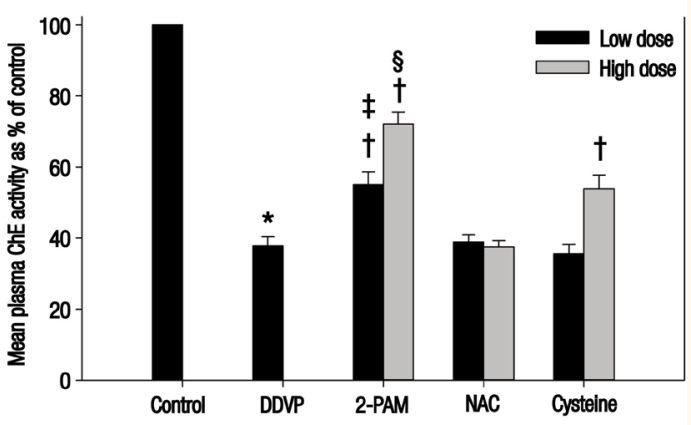

Figure 1: Chart showing mean plasma cholinesterase activity in different experimental groups as a measure of human cholinesterase reactivation in the treatment of organophosphide poisoning $(\mathrm{N}=22)$. The dichlorvos group was compared with the control group while all other groups were compared with the dichlorvos group. $C h E=$ cholinesterase; $D D V P=$ dichlorvos; $2-P A M=$ pralidoxime; $N A C=N$-acetylcysteine.

"Statistically significant difference in comparison to the control group $(P<0.010){ }^{+}$Statistically significant difference in comparison to the dichlorvos group $(P<0.010)$. Ftatistically significant difference in comparison to a low dose of cysteine $(P<0.010)$. ${ }^{5}$ Statistically significant difference in comparison to a low dose of 2-PAM $(P<0.010)$

increase BuChE activity over dichlorvos $(P>0.050$ each). A high dose of NAC $(37.5 \% \pm 1.7 \%)$ also did not significantly increase BuChE activity in comparison to dichlorvos $(P>0.050)$. However, a high concentration of cysteine $(53.8 \% \pm 3.9 \%)$ significantly increased BuChE activity over that of dichlorvos $(P<0.010)$. A high concentration of 2-PAM significantly increased BuChE activity in comparison to a low concentration $(P<0.010)$. Moreover, a low dose of 2 -PAM significantly increased BuChE activity in comparison to a low dose of cysteine $(P<0.010)$ [Figure 1 ].

AChE activity was significantly reduced in the dichlorvos group compared to the control group $(60.0 \% \pm 2.5 \% ; P<0.010)$, although to a lesser extent than for BuChE activity. Both low and high doses of 2 -PAM $(81.9 \% \pm 2.4 \%$ and $94.6 \% \pm 2.8 \%$, respectively) significantly increased AChE activity over that of dichlorvos $(P<0.010$ each). Low and high concentrations of NAC $(63.0 \% \pm 2.0 \%$ and $67.1 \% \pm$ $4.7 \%$, respectively) did not significantly increase $\mathrm{AChE}$ activity in comparison to dichlorvos ( $P>0.050$ each). Low and high concentrations of cysteine $(75.0 \% \pm$ $3.3 \%$ and $88.7 \% \pm 3.4 \%$, respectively) significantly increased AChE activity compared to the dichlorvos group ( $P<0.010$ and $<0.010$, respectively). There was no significant difference between low and high concentrations of 2-PAM or low concentrations of 2-PAM and cysteine in terms of AChE activity ( $P>0.050$ each). There was also no significant difference between high concentrations of 2-PAM and cysteine with regards to AChE activity. However, a high dose of 2-PAM significantly increased AChE activity over that of a low cysteine dose $(P<0.010)$ [Figure 2].

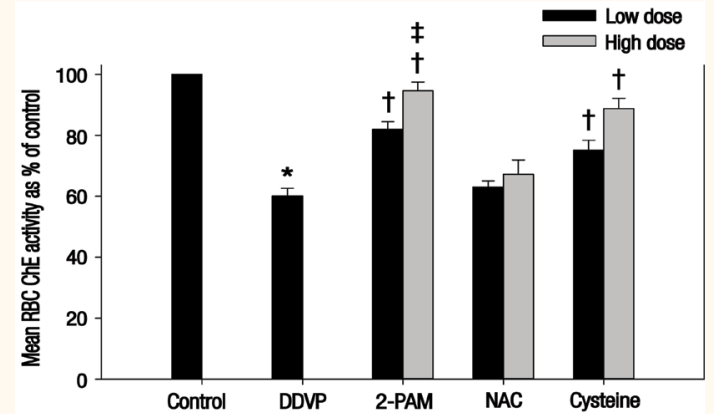

Figure 2: Chart showing mean red blood cell cholinesterase activity in different experimental groups as a measure of human cholinesterase reactivation in the treatment of organophosphide poisoning $(\mathrm{N}=22)$. The dichlorvos group was compared with the control group while all other groups were compared with the dichlorvos group.

$R B C=$ red blood cell $;$ ChE $=$ cholinesterase; $D D V P=$ dichlorvos 2-PAM = pralidoxime; $N A C=N$-acetylcysteine

"Statistically significant difference in comparison to the control group $(P<0.010))^{\dagger}$ Statistically significant difference in comparison to the dichlorvos group $(P<0.010)$. ${ }^{*}$ Statistically significant difference in comparison to a low dose of cysteine $(P<0.010)$.

\section{Discussion}

Previous research has indicated that NAC replenishes glutathione storage and has antioxidant and free radical scavenging properties. ${ }^{19}$ It is a prodrug which is enzymatically metabolised (i.e. deacetylated) by the liver into its active metabolite cysteine and serves as a cysteine donor. ${ }^{20}$ The thiol group of cysteine is reactive toward xenobiotics and seems to be responsible for its beneficial effects in poisoning cases. ${ }^{21}$ In the present study, the reactivation effect of equimolar concentrations of 2-PAM, NAC and cysteine on dichlorvos-induced BuChE and AChE inhibition was investigated. The results demonstrated that dichlorvos inhibited BuChE activity to a greater degree than AChE activity; this finding is in agreement with a statement by Jafari et al. indicating that AChE is less sensitive to OPs than BuChE. ${ }^{22}$ Ríos et al. have previously shown that while 2-PAM concentrations as low as $66 \mu \mathrm{mol} . \mathrm{L}^{-1}$ are sufficient to prevent deaths in most in vivo cases of OP poisoning, concentrations of up to $700 \mu \mathrm{mol.L-}{ }^{1}$ are much more effective. ${ }^{23}$ In the present study, samples were treated with both low $\left(300 \mu \mathrm{mol} . \mathrm{L}^{-}{ }^{1}\right)$ and high $\left(600 \mu \mathrm{mol} . \mathrm{L}^{-1}\right)$ concentrations of 2-PAM in order to compare $\mathrm{ChE}$ reactivation effects; the results showed that a high concentration of 2-PAM increased BuChE but not AChE activity in comparison to a low concentration. These findings confirm that ChE reactivation in OP poisoning is dependent on the plasma concentrations of 2-PAM. ${ }^{23}$

The concentrations of 2-PAM, NAC and cysteine in the current study were selected based on their therapeutic plasma concentrations in humans. ${ }^{23,24}$ The 
standard intravenous regimen of NAC $-150 \mathrm{mg} / \mathrm{kg}^{-1}$ for 15 minutes followed by $50 \mathrm{mg} / \mathrm{kg}-1$ for four hours and $100 \mathrm{mg} / \mathrm{kg}^{-1}$ over the next 16 hours-produces initial NAC plasma concentrations ranging from 304-875 $\mu \mathrm{g} \cdot \mathrm{mL}^{-1}{ }^{124}$ Concentrations subsequently fall rapidly and reach a relatively constant level of approximately $35 \mu \mathrm{g} . \mathrm{mL}^{-1}$ after 12 hours until the infusion is stopped. ${ }^{24}$ In comparison to dichlorvos, concentrations of NAC in the present study did not significantly increase $\mathrm{BuChE}$ and $\mathrm{AChE}$ activities; however, both BuChE and AChE activities significantly increased with concentrations of cysteine. This finding indicates that cysteine, the active metabolite of $\mathrm{NAC}$, is responsible for the reactivation of ChEs. The absence of a metabolising organ-the liver-in the present in vitro study may explain why NAC did not elevate BuChE and AChE activities in comparison to cysteine. ${ }^{20}$ Thus, in clinical situations in which liver function is normal, NAC treatment may still be effective. The results of the present work indicate that therapeutic plasma concentrations of cysteine (or, potentially, NAC) for the treatment of OP poisoning strongly depends on OP plasma concentrations.

The $\mathrm{pK}_{\mathrm{a}}$ of nucleophiles has been shown to play an important role in their reaction with OPs, in that more basic nucleophiles with higher $\mathrm{pK}_{\mathrm{a}}$ values show a lower reactivity. ${ }^{2,25}$ The $\mathrm{pK}_{\mathrm{a}}$ values of the 2-PAM oxime and cysteine thiol groups are 7.8 and 8.3, respectively, which reflect a favourable range. ${ }^{2,26}$ In addition, according to the Henderson-Hasselbalch equation, the 2-PAM oxime and cysteine thiol groups are $28.48 \%$ and $11.18 \%$ ionised at a $\mathrm{pH}$ of 7.4 , respectively. ${ }^{2}$ Thus, it is expected that, in addition to 2-PAM, cysteine could also react with the OP-ChE complex and displace OP with a nucleophilic attack, resulting in the reactivation of ChEs. With a $\mathrm{pK}_{\mathrm{a}}$ of 9.5, NAC is less reactive to nucleophiles than cysteine. ${ }^{27}$ For a nucleophilic attack of the cysteine thiol group to the phosphorus-oxygen bond of the OP-ChE complex, the phosphorus-oxygen bond between the serine hydroxyl oxygen atom from $\mathrm{ChE}$ and the phosphorous atom of OP should be cleaved and a phosphorus-sulfur bond formed between the cysteine thiol sulfur atom and the phosphorus atom of OP. Cysteine is a weak nucleophile and the phosphorus-sulfur bond is much weaker than a phosphorus-oxygen bond and therefore easier to break; however, the concentration of the reactants, namely cysteine and OP, seems to play a critical role in this reaction. ${ }^{28,29}$ On the basis of collision theory, a higher concentration of reactants increases the probability of effective collisions, consequently resulting in the formation of a product. ${ }^{30}$ However, to be effective, collisions should occur in a particular molecular orientation.
In the present study, concentrations of dichlorvos and cysteine were $0.95 \mu \mathrm{mol.L-}{ }^{1}$ and $300 \mu \mathrm{mol.L-}{ }^{1}$ (low dose) and $600 \mu \mathrm{mol}_{\text {. }}{ }^{-1}$ (high dose), respectively. In clinical cases of OP poisoning, the plasma concentration of OP is very high due to the high intake. ${ }^{31}$ Thus, large amounts of NAC and even 2-PAM should be administered intravenously to be effective. Some researchers have reported that although intravenous NAC reduced hospitalisation time among OPpoisoned individuals, it unfortunately did not increase ChE activity. ${ }^{11}$ One explanation for this outcome may be related to the low plasma concentration of NAC in comparison to the high plasma concentration of OP. Another explanation may be related to the direct reaction of NAC-or, more accurately, cysteine-with OPs which results in more polar and may be more excretable product. ${ }^{2}$ A similar result has been observed with the administration of 2-PAM to OP-poisoned individuals, in that $\mathrm{ChE}$ reactivation seems to depend on the plasma concentrations of 2-PAM and OP, with high concentrations of 2-PAM necessary for the adequate reactivation of OP-inhibited human RBC $\mathrm{ChEs}^{23}$ This phenomenon explains why oximes are not always useful in the management of OP poisoning. ${ }^{6-8}$

Figure 3 illustrates the proposed mechanism of nucleophilic attack of 2-PAM and cysteine to dichlorvos, in which the reactions of 2-PAM and cysteine with dichlorvos proceed through an associative stepwise addition-elimination mechanism. ${ }^{2}$ In both of these reactions, the 2,2-dichlorovinylate anion (as a leaving group) is separated from a pentacoordinate phosphorene intermediate and leaves a polar product which seems to be more excretable than dichlorvos. The 2,2-dichlorovinylate anion then gains a hydrogen ion and is converted to 2,2-dichlorovinyl alcohol which in turn undergoes a spontaneous rearrangement and is converted to dichloroacetaldehyde, a metabolite of dichlorvos. ${ }^{2}$ One of the detoxification mechanisms of $\mathrm{NAC}$ in acetaminophen poisoning is its direct reaction with $\mathrm{N}$-acetyl-p-benzoquinone imine, the toxic metabolite of acetaminophen. ${ }^{19}$ Thus, NAC may still act as an antidote in OP poisoning due to its direct reaction and neutralisation properties. On this basis, Figure 4 depicts another proposed mechanism for the reactivation of OP-inhibited ChEs by 2-PAM and cysteine wherein the reactions of 2-PAM and cysteine with OP-inhibited ChEs also proceed via an associative stepwise addition-elimination process. Similarly, the serine anion of $\mathrm{ChE}$ as a leaving group is separated from a pentacoordinate phosphorane intermediate in both of these reactions.

The $\mathrm{pK}_{\mathrm{a}}$ of the leaving group has also been shown to play an important role in the reaction of nucleophiles, as more acidic leaving groups with low $\mathrm{pK}_{\mathrm{a}}$ values are 
A

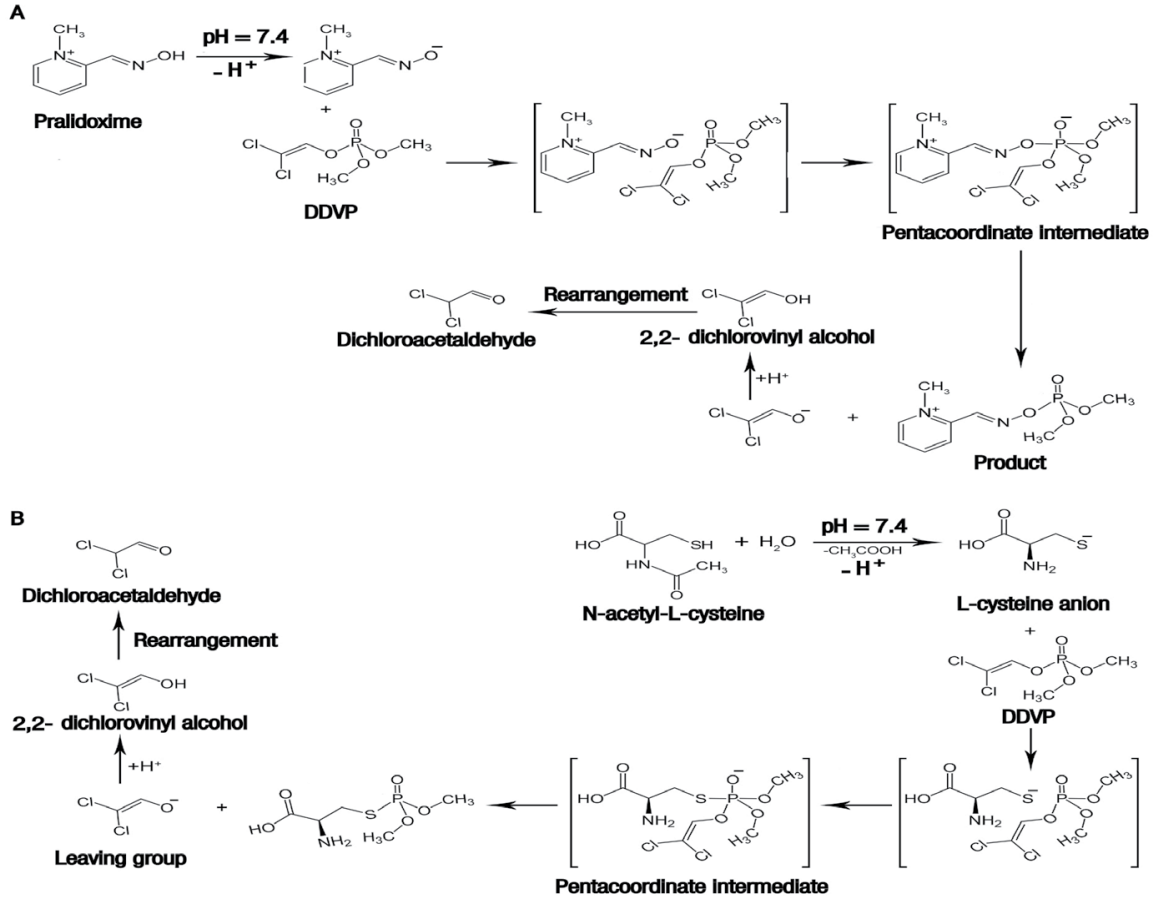

Figure 3: Diagram showing a proposed nucleophilic mechanism for the reaction of (A) pralidoxime and (B) N-acetylcysteine with dichlorvos.

$\mathrm{CH}_{3} / \mathrm{H}_{3} \mathrm{C}=$ methyl group; $\mathrm{N}=$ nitrogen; $\mathrm{OH}=$ hydroxide; $\mathrm{H}=$ hydrogen; $\mathrm{Cl}=$ chlorine; $\mathrm{O}=$ oxygen; $\mathrm{P}=$ phosphorus; $\mathrm{DDVP}=$ dichlorvos; $\mathrm{NH}_{2}=$ amine group; $\mathrm{S}=$ sulfur.

Figure 3 A reproduced with permission from Shetab-Boushehri SV, Shetab-Boushehri SF, Abdollahi M. Possible role of Mg2+ ion in the reaction of organophosphate (dichlorvos) with serine. ${ }^{2}$

\section{A}
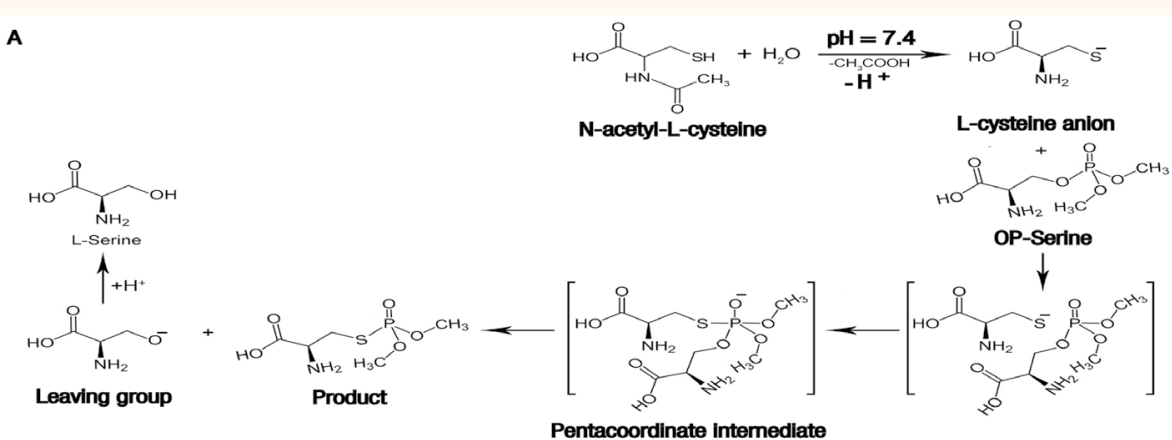

B

Pentacoordinate intemediate

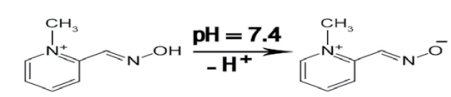

Pralidoxime
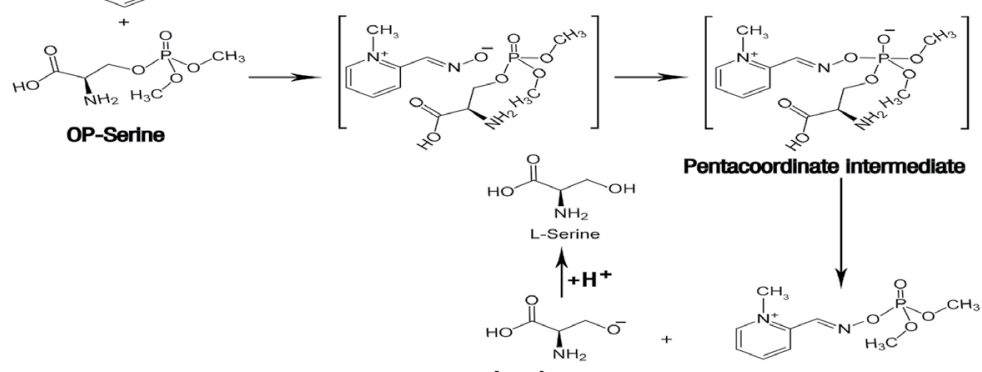

Pentacoordinate intermedlate

Leaving group

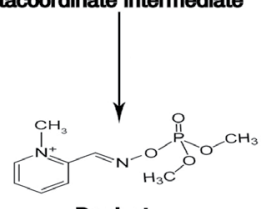

Figure 4: Diagram showing a proposed nucleophilic mechanism for the reaction of (A) pralidoxime and (B) $\mathrm{N}$-acetylcysteine with the dichlorvos-cholinesterase complex. For simplification, only the serine moiety of cholinesterase is shown.

$\mathrm{CH}_{3} / \mathrm{H}_{3} \mathrm{C}=$ methyl group $\mathrm{N}=$ nitrogen $; \mathrm{OH}=$ hydroxide; $\mathrm{H}=$ hydrogen $; \mathrm{O}=$ oxygen $; \mathrm{NH}_{2}=$ amine group; $\mathrm{P}=$ phosphorus $\mathrm{OP}=$ organophosphate; $\mathrm{S}=$ sulfur; $\mathrm{HN}=$ amine; $\mathrm{SH}=$ thiol; $\mathrm{H}_{2} \mathrm{O}=$ water. 
more easily separated from OPs. ${ }^{25}$ This could explain why certain OPs more rapidly age ChEs in comparison to others. ${ }^{5}$ In the current study, the displacement of serine as a leaving group with a $\mathrm{pK}_{\mathrm{a}}$ of 13.0 by 2-PAM and cysteine as nucleophiles with $\mathrm{pK}_{\mathrm{a}} \mathrm{s}$ of 7.8 and 8.3 , respectively, seems thermodynamically unfavourable $;^{2,26}$ nevertheless, clinical evidence as well as the results of the present study show that although 2-PAM has a lower $\mathrm{pK}_{\mathrm{a}}$ than serine, it displaces the serine moiety in the OP-ChE complex which results in reactivated ChEs. ${ }^{3,4,8,9}$ Cysteine, although a weaker nucleophile, seems to follow this mechanism but at much higher plasma concentrations. As in the case of direct reactions of 2-PAM and cysteine with dichlorvos, the displacement of the serine moiety of the OP-AChE complex by 2-PAM and cysteine seems to be dose-dependent. Although cysteine is a weak nucleophile, the current study demonstrates that it nevertheless displaces the serine moiety in the OPChE complex at high concentrations.

The authors suggest the administration of a maximum tolerable intravenous dose of NAC for the treatment of OP poisoning; however, extensive animal studies are needed to confirm this suggestion and NAC should be considered a supportive antidote until the safety and efficacy of this approach is approved. Considering its potential for metabolising into cysteine, NAC could be an alternative therapeutic agent in OP poisoning. A comparative animal study on the beneficial effects of NAC and cysteine on the reactivation of ChEs in $\mathrm{OP}$ poisoning is therefore proposed for future research.

\section{Conclusion}

The results of the present study suggest that the direct reactions of 2-PAM and cysteine with dichlorvos, and the subsequent reactivation of phosphorylated ChEs, proceed through an associative stepwise addition-elimination process. In addition, the findings indicate that cysteine directly reacts with OPs at low concentrations while, at very high concentrations, it replaces serine in the pentacoordinate intermediate and regenerates inhibited ChEs as well as directly reacting with dichlorvos. Moreover, it is possible that higher doses of NAC in a clinical context may also have the same effect; however, further studies are required to confirm this theory.

\section{ACKNOWLEDGEMENTS}

The authors thank the Gyah Corporation for providing the purified dichlorvos used in the present study.

\section{CONFLICT OF INTEREST}

The authors declare no conflicts of interest.

\section{FUNDING}

This study was funded with the aid of a grant from the Mazandaran University of Medical Sciences (grant\#1072).

\section{References}

1. Kirby AJ, Mora JR, Nome F. New light on phosphate transfer from triesters. Biochim Biophys Acta 2013; 1834:454-63. doi: 10. 1016/j.bbapap.2012.04.010

2. Shetab-Boushehri SV, Shetab-Boushehri SF, Abdollahi M. Possible role of $\mathrm{Mg} 2+$ ion in the reaction of organophosphate (dichlorvos) with serine. J Med Hypotheses Ideas 2012; 6:53-7. doi: 10.1016/j.jmhi.2012.05.001

3. Sidhu G, Jandial S, Khubchandani A. A study of erythrocyte cholinesterase in comparison with serum cholinesterase activity in organophosphorous poisoning patients. Int J Res Med 2014; 3:77-9.

4. Santarpia L, Grandone I, Contaldo F, Pasanisi F. Butyrylcholinesterase as a prognostic marker: A review of the literature. J Cachexia Sarcopenia Muscle 2013; 4:31-9. doi: 10.1007/s13539012-0083-5.

5. Sirin GS, Zhang Y. How is acetylcholinesterase phosphonylated by soman? An ab initio QM/MM molecular dynamics study. J Phys Chem A 2014; 118:9132-9. doi: 10.1021/jp502712d.

6. Rahimi R, Nikfar S, Abdollahi M. Increased morbidity and mortality in acute human organophosphate-poisoned patients treated by oximes: A meta-analysis of clinical trials. Hum Exp Toxicol 2006; 25:157-62. doi: 10.1191/0960327106ht602oa.

7. Abdollahi M, Behmanesh Y, Akhgari M. The effects of oximes in the assay of acetylcholinesterase activity in lysed erythrocytes in vitro. Acta Med Iran 1997; 35:45-8.

8. Nurulain SM. Efficacious oxime for organophosphorus poisoning: A minireview. Trop J Pharm Res 2011; 10:341-9. doi: 10.4314/tjpr. v10i3.10.

9. Johnson MK, Jacobsen D, Meredith TJ, Eyer P, Heath AJ, Ligtenstein DA, et al. Evaluation of antidotes for poisoning by organophosphorus pesticides. Emergen Med Australas 2000; 12:22-37. doi: 10.1046/j.1442-2026.2000.00087.x.

10. Prescott L. Oral or intravenous $\mathrm{N}$-acetylcysteine for acetaminophen poisoning? Ann Emerg Med 2005; 45:409-13. doi: 10.1016 /j.annemergmed.2004.09.028

11. Shadnia S, Ashrafivand S, Mostafalou S, Abdollahi M. N-acetylcysteine a novel treatment for acute human organophosphate poisoning. Int J Pharmacol 2011; 7:732-5. doi: 10.3923/ijp.2011. 732.735

12. Liu R, Nair D, Ix I, Moore DH, Bent S. N-acetylcysteine for the prevention of contrast-induced nephropathy: A systematic review and meta-analysis. J Gen Intern Med 2005; 20:193-200. doi: 10.1111/j.1525-1497.2005.30323.x.

13. Palma PC, Villaça Júnior CJ, Netto Júnior NR. N-acetylcysteine in the prevention of cyclophosphamide induced haemorrhagic cystitis. Int Surg 1986; 71:36-7.

14. Berk M, Malhi GS, Gray LJ, Dean OM. The promise of $\mathrm{N}$-acetylcysteine in neuropsychiatry. Trends Pharmacol Sci 2013; 34:167-77. doi: 10.1016/j.tips.2013.01.001.

15. Geiler J, Michaelis M, Naczk P, Leutz A, Langer K, Doerr HW, et al. N-acetyl-L-cysteine (NAC) inhibits virus replication and expression of pro-inflammatory molecules in A549 cells infected with highly pathogenic H5N1 influenza A virus. Biochem Pharmacol 2010; 79:413-20. doi: 10.1016/j.bcp.2009.08.025. 
16. Young DS, Bermes EW. Specimen collection and processing: Sources of biological variation. In: Burtis CA, Ashwood ER, Eds. Tietz Textbook of Clinical Chemistry, 3rd ed. Philadelphia, Pennsylvania, USA: Saunders, 1999. Pp. 42-72.

17. Lotti M, Johnson MK. Neurotoxicity of organophosphorus pesticides: Predictions can be based on in vitro studies with hen and human enzymes. Arch Toxicol 1978; 41:215-21. doi: 10.10 07/BF00354093.

18. Ellman GL, Courtney KD, Andres V Jr, Featherstone RM. A new and rapid colorimetric determination of acetylcholinesterase activity. Biochem Pharmacol 1961; 7:88-95. doi: 10.1016/00062952(61)90145-9.

19. Asevedo E, Mendes AC, Berk M, Brietzke E. Systematic review of $\mathrm{N}$-acetylcysteine in the treatment of addictions. Rev Bras Psiquiatr 2014; 36:168-75. doi: 10.1590/1516-4446-2013-1244.

20. Cacciatore I, Cornacchia C, Pinnen F, Mollica A, Di Stefano A. Prodrug approach for increasing cellular glutathione levels. Molecules 2010; 15:1242-64. doi: 10.3390/molecules15031242.

21. Heidari R, Babaei H, Roshangar L, Eghbal MA. Effects of enzyme induction and/or glutathione depletion on methimazole-induced hepatotoxicity in mice and the protective role of $\mathrm{N}$-acetylcysteine. Adv Pharm Bull 2014; 4:21-8. doi: 10.5681/apb.2014.004.

22. Jafari M, Pourheidari G. The reactivation effect of pralidoxime in human blood on parathion and paraoxon-induced cholinesterase inhibition. Daru 2006; 14:37-43.

23. Ríos JC, Repetto G, Galleguillos I, Jos A, Peso AD, Repetto M. High concentrations of pralidoxime are needed for the adequate reactivation of human erythrocyte acetylcholinesterase inhibited by dimethoate in vitro. Toxicol In Vitro 2005; 19:893-7. doi: 10.1016/j.tiv.2005.06.024
24. Prescott LF, Donovan JW, Jarvie DR, Proudfoot AT. The disposition and kinetics of intravenous $\mathrm{N}$-acetylcysteine in patients with paracetamol overdosage. Eur J Clin Pharmacol 1989; 37:501-6. doi: 10.1007/BF00558131.

25. Lassila JK, Zalatan JG, Herschlag D. Biological phosphoryl transfer reactions: Understanding mechanism and catalysis. Annu Rev Biochem 2011; 80:669-702. doi: 10.1146/annurev-bio chem-060409-092741.

26. Kennelly PJ, Rodwell VW. Amino acids \& peptides. In: Rodwell VW, Bender DA, Botham KM, Kennelly PJ, Weil PA. Harper's Illustrated Biochemistry, 30th ed. New York, USA: McGraw-Hill, 2015. Pp. 15-24.

27. Moffat AC, Osselton MD, Widdop B, Eds. Clarke's Analysis of Drugs and Poisons, 4th ed. London, UK: Pharmaceutical Press, 2011. P. 823.

28. Iyer S, Hengge AC. The effects of sulfur substitution for the nucleophile and bridging oxygen atoms in reactions of hydroxyalkyl phosphate esters. J Org Chem 2008; 73:4819-29. doi: 10.1021 /jo8002198.

29. Haynes WM. CRC Handbook of Chemistry and Physics, 95th ed. Boca Raton, Florida, USA: CRC Press, 2014. Pp. 9-69.

30. Silberberg M. Principles of General Chemistry, 2nd ed. New York, USA: McGraw-Hill, 2009. P. 529.

31. Futagami K, Otsubo K, Nakao Y, Aoyama T, Iimori E, Urakami S, et al. Acute organophosphate poisoning after disulfoton ingestion. J Toxicol Clin Toxicol 1995; 33:151-5. doi: 10.3109/155636595 09000465. 